\title{
Identification and characterization of microsatellite markers from the tropical sea cucumber, Stichopus horrens (Selenka)
}

\author{
J.B. Shangguan, Z.B. Li, Y. Yuan and Y.S. Huang \\ Fisheries College, Jimei University, Xiamen, China \\ Corresponding author: Z.B. Li \\ E-mail: lizhongbao@jmu.edu.cn \\ Genet. Mol. Res. 14 (4): 13582-13587 (2015) \\ Received June 10, 2015 \\ Accepted September 2, 2015 \\ Published October 28, 2015 \\ DOI http://dx.doi.org/10.4238/2015.October.28.18
}

Fujian Provincial Key Laboratory of Marine Fishery Resources and Eco-Environment,

\begin{abstract}
Tropical commercial sea cucumber Stichopus horrens is extensively distributed throughout the tropical Indo-Pacific region, and wild stocks have been severely depleted over the past decade. In this study, we used the microsatellite enrichment library of $S$. horrens to identify and characterize 13 microsatellite loci, including 11 polymorphic loci and 2 monomorphic loci. Among the 11 polymorphic loci, the number of alleles was 3-8. The observed and expected heterozygosity varied from 0.1364 to 0.8966 and from 0.1653 to 0.7551 , respectively. Additionally, all 11 polymorphic loci showed moderate and high polymorphism with the polymorphism information content (0.271-0.7311). A total of 9 polymorphic loci were in Hardy-Weinberg equilibrium, except for 2 loci (adjusted $P=0.004545$ ). Linkage disequilibrium was not detected in any pairs of polymorphic loci. The present study will be useful for studying genetic structure, population conservation, and breeding of wild S. horrens; moreover, our results contribute to the phylogeny and evolutionary research of Holothuroidea.
\end{abstract}

Key words: Fast isolation method with amplified fragment length polymorphism of sequences containing repeats; Microsatellite markers; Stichopus horrens; Tropical commercial sea cucumber 


\section{INTRODUCTION}

The tropical sea cucumber, Stichopus horrens, Selenka, 1867 (Echinodermata: Holothuroidea), is widely distributed in the west Pacific from Malaysia to Society Islands, around French Polynesia, and from Southern Japan and Hawaii to New Caledonia (Schoppe, 2000; Massin, et al., 2002; Hearn and Pinillos, 2006). With its greyish background color and its very large conical, dorsal papillae, particularly the only species with tack-like tables among Stichopus species, S. horrens is easy to identify among Stichopus species (Massin, et al., 2002). Stichopus horrens typically roosts in shallow sea areas within $15 \mathrm{~m}$, hides itself under coral and rocks, and is nocturnal (Schoppe, 2000).

As a commercial sea cucumber in China, $S$. horrens is harvested for traditional medicine and delicacies, and is generally consumed worldwide (Baine and Choo, 1999; Chen, 2003; Rasolofonirina et al., 2004). However, over-fishing and habitat destruction have severely depleted the wild resources of S. horrens. Microsatellites, or simple sequence repeats (SSRs), are stretches of DNA consisting of tandemly repeated short units of 1-6 base pairs (bp) in length and are ubiquitous in prokaryotes and eukaryotes (Beckmann and Weber, 1992; Chistiakov, 2006). The microsatellite marker is popular in the field of population genetics research as the second generation of molecular marker technology. Additionally, genetic studies of $S$. horrens are rather limited, except for 16microsatellite loci developed by Yuan et al. (2012). The demand for sea cucumbers in China and abroad is increasing, and thus it is urgent to take immediate measures to maintain the natural population and implement sustainable practices in southern China, such as closed seasons/areas, captivity, aquaculture, and breeding (Yuan, 2012; Hu, 2013).

In this study, we conducted genetic characterization of 13 novel microsatellite loci, including 11 polymorphic loci and 2 monomorphic loci. Our results provide new basic information for genetic studies of $S$. horrens, such as genomic structure, population diversity, phylogenetic analyses, and cross-amplification among related species.

\section{MATERIAL AND METHODS}

\section{Specimen collection and genomic DNA extraction}

Thirty-five wild adult S. horrens individuals were collected in Sanya, Hainan Province, China. After dissection, each body wall of the samples were soaked in $100 \%$ alcohol, transported to the laboratory, and stored at $-20^{\circ} \mathrm{C}$. High-quality genomic DNA was extracted from the body wall of 35 samples using the TIANamp Marine Animals DNA Kit (Tiangen Biotech, Beijing, China), followed by purification with EZNA ${ }^{\mathrm{TM}}$ Cycle-Pure Kit (Omega Bio-Tek, Norcross, GA, USA), and then examined by $1 \%$ agarose gel electrophoresis and a superfine ultraviolet spectrophotometer.

\section{Microsatellite-enriched library construction}

The process of microsatellite-enriched library construction was based on a modified fast isolation method with amplified fragment length polymorphism of sequences containing repeats (Zane et al., 2002). First, $20 \mu \mathrm{L} 100 \mathrm{ng} / \mu \mathrm{L}$ satisfactory genomic DNA mixed with 4 randomly selected samples was digested into 300-1200-bp fragments with $1 \mu \mathrm{L}$ Tru1l (Msel) (Thermo Scientific, Waltham, MA, USA) restriction enzyme in $25 \mu \mathrm{L}$ at $65^{\circ} \mathrm{C}$ for $3 \mathrm{~h}$ and $80^{\circ} \mathrm{C}$ for 
$10 \mathrm{~min}$. The digested products with sticky ends were linked to pretreated adapters (adapter A5'GACGATGAGTCCTGAG-3' and adapter B5'-TACTCAGGACTCAT-3') by T4 DNA Ligase (Thermo Scientific) at $37^{\circ} \mathrm{C}$ for $3.5 \mathrm{~h}$. Following denaturation of the adapter-ligated products, the library was hybridized to (CT)15 and (GT)15 probes labeled with biotin at $61^{\circ} \mathrm{C}$ for $1 \mathrm{~h}$. Subsequently, the target fragments containing microsatellite SSRs were captured using streptavidin-coated magnetic beads (Promega Corporation, Madison, WI, USA). After elution, the highly purified SSR products were amplified by polymerase chain reaction (PCR) using the above adapter A. Finally, $4 \mu \mathrm{L}$ microsatellite enriched library was ligated into $1 \mu \mathrm{L}$ PMD19-Tvector (TaKaRa, Shiga, Japan) at $16^{\circ} \mathrm{C}$ for $3.5 \mathrm{~h}$, and then the recombinant plasmids were introduced into Escherichia coli $\mathrm{DH} 5 \alpha$ strains (Tiangen Biotech) for further selection on LuriaBertani agar medium containing $100 \mu \mathrm{g} / \mathrm{mL}$ ampicillin. Positive monoclones were randomly obtained, amplified using M13 general primers, and evaluated by $1 \%$ agarose gelselectrophoresis. The selected fragments of $400-1000$ bp were sequenced by Life Technologies (Carlsbad, CA, USA).

\section{Microsatellite sequence discovery and primer screening}

After the vector and adapters were removed from the sequenced results, sequences containing a perfect microsatellite motif of at least 5 repetitions for any microsatellite motif of 1-6 bp were selected using SSR hunter 1.3 software for further analyses (Li and Wan, 2005). Next, microsatellite amplification-specific primers were designed from applicable flanking sequences using Primer Premier 5.0. The optimum annealing temperature of different primers was screened by gradient temperature PCR and a mixture of DNA template.

\section{DNA amplification and genotyping}

Some microsatellite markers were tested for polymorphisms using a panel of 30 genomic DNA samples selected from the above 35 wild individuals after preliminary screening of all primers. The protocol for PCR was conducted in a $10-\mu \mathrm{L}$ volume: $100 \mathrm{ng} / \mu \mathrm{L}$ template genomic DNA, 10X Dream Taq Buffer, $10 \mathrm{mM}$ dNTPs, $5 \mathrm{U} / \mu \mathrm{L}$ Dream Taq DNA polymerase, and $10 \mu \mathrm{M}$ forward and reverse primers. PCR was performed under the following cyclic conditions: $95^{\circ} \mathrm{C}$ for $5 \mathrm{~min}$; followed by 35 cycles of $94^{\circ} \mathrm{C}$ for $40 \mathrm{~s}$, annealing temperature (Table 1) for $40 \mathrm{~s}$ and $72^{\circ} \mathrm{C}$ for $1 \mathrm{~min}$; final extension at $72^{\circ} \mathrm{C}$ for $20 \mathrm{~min}$. The PCR products were separated using $6 \%$ polyacrylamide gels in a vertical Sequi-Gen Sequencing Cell (Bio-Rad, Hercules, CA, USA) at a constant temperature of $50^{\circ}-55^{\circ} \mathrm{C}$. Additionally, 10-bp DNA ladder (Invitrogen, Carlsbad, CA, USA) was used as a size standard. Finally, the gels were visualized by silver staining and documented by counting the alleles.

\section{Microsatellite data analysis}

Null alleles and scoring errors of all SSR loci were assessed using MICRO-CHECKER ver. 2.2.3 (Van Oosterhout et al., 2004). POPGENE 32 (version 1.32) (Yeh et al., 2000) was used to evaluate genotypic linkage disequilibrium, Hardy-Weinberg equilibrium, observed heterozygosities, and expected heterozygosities. Significance values were adjusted for multiple comparisons using Bonferroni corrections when necessary (Rice, 1989). The number of alleles per locus and the polymorphism information content were estimated using CERVUS 3.0 (version 3.0). 
Table 1. Basic genetic information of 13 microsatellite loci in $S$. horrens ( $N=30$ individuals).

\begin{tabular}{|c|c|c|c|c|c|c|c|c|c|}
\hline Locus & Primer sequences $\left(5^{\prime}-3^{\prime}\right)$ & $\mathrm{Ta}\left({ }^{\circ} \mathrm{C}\right)$ & Repeat motif & Allele size (bp) & $N_{\mathrm{A}}$ & PIC & $H_{0}$ & $H_{\mathrm{E}}$ & GenBank No. \\
\hline $\operatorname{sh} 1^{*}$ & $\begin{array}{l}\text { F: ATACAAGCACACAGTCAGACACAT } \\
\text { R: TTTAGTTTGATAGTACCACGGAGC }\end{array}$ & 47.0 & $(\mathrm{AC})_{28}$ & $128-138$ & 4 & 0.600 & 0.1429 & 0.5091 & KR653147 \\
\hline sh2 & $\begin{array}{l}\text { F: GTAGAAAATCTGGAAAGCAACA } \\
\text { R: CGGTAACCTTAGTCGTATGACA }\end{array}$ & 40.0 & $(\mathrm{TTTA})_{3} \mathrm{~T}_{11}$ & $230-240$ & 3 & 0.309 & 0.2857 & 0.2449 & KR653148 \\
\hline $\operatorname{sh} 3^{*}$ & $\begin{array}{l}\text { F: ACGAACTGGTTTTGCTGCG } \\
\text { R: TGGCTATATCCATTGGCGG }\end{array}$ & 47.0 & $(A G)_{25}$ & $400-410$ & 3 & 0.545 & 0.1364 & 0.4163 & KR653149 \\
\hline sh4 & $\begin{array}{l}\text { F: GCAGCAAAGCATAGCCAACA } \\
\text { R: GTCTCTCTACCGCCACCCAC }\end{array}$ & 40.0 & $(\mathrm{AG})_{46}$ & $158-165$ & 4 & 0.580 & 0.6842 & 0.4668 & KR653150 \\
\hline sh5 & $\begin{array}{l}\text { F: GCTGTGACTTGTGATGAG } \\
\text { R: GATACTGTGTAGGTGTGC }\end{array}$ & 51.8 & $T_{12}$ & 195-205 & 3 & 0.554 & 0.6957 & 0.4537 & KR653151 \\
\hline sh6 & $\begin{array}{l}\text { F: AAAGTTATGACAGCGGGTGAT } \\
\text { R: CAGCAGTATGTAGTCCGTGAA }\end{array}$ & 42.0 & $(\mathrm{AG})_{31}$ & $155-160$ & 3 & 0.584 & 0.5455 & 0.4959 & KR653152 \\
\hline sh7 & $\begin{array}{l}\text { F: CAACAAAGTAAAAAGGAGGTGGGG } \\
\text { R: CGGAAAAAGTGGCTTATGTCAGAG }\end{array}$ & 45.0 & $\mathrm{~T}_{15}$ & $210-220$ & 3 & 0.382 & 0.4643 & 0.3565 & KR653153 \\
\hline sh8 & $\begin{array}{l}\text { F: GAAAAACGGAAAGGAGAAGAG } \\
\text { R: CGTACACCTATGTATGCGGAC }\end{array}$ & 53.0 & $(\mathrm{AG})_{29}(\mathrm{TG})_{23}$ & $180-190$ & 3 & 0.412 & 0.1818 & 0.1653 & KR653154 \\
\hline sh9 & $\begin{array}{l}\text { F: CCACCGACACAGGAACAAA } \\
\text { R: CGCAGGTCAAATCAGCAAA }\end{array}$ & 48.6 & $(\mathrm{AC})_{48} \mathrm{AT}\left(\mathrm{A}_{\mathrm{C}}\right)_{5}$ & $270-280$ & 3 & 0.476 & 0.5769 & 0.4105 & KR653155 \\
\hline $\operatorname{sh} 10$ & $\begin{array}{l}\text { F: TGTGTGTAGGCTATGTGAAA } \\
\text { R: AACGAGATAAATGCGTGAAG }\end{array}$ & 42.0 & $\mathrm{C}_{12}$ & $160-180$ & 8 & 0.734 & 0.8966 & 0.7551 & KR653156 \\
\hline sh11 & $\begin{array}{l}\text { F: GAGGAAGAAAAAACAAAAGAA } \\
\text { R: AAAACAGCAATAATAGAACAT }\end{array}$ & 47.0 & $(\mathrm{TG})_{5}$ & $100-105$ & 3 & 0.271 & 0.1429 & 0.1913 & KR653157 \\
\hline sh12 & $\begin{array}{l}\text { F: CTCCTTAGTGAAAGTTATGACAGCG } \\
\text { R: ACACTTGAGGGTATATAGCCAGGTC }\end{array}$ & 46.5 & $(\mathrm{AG})_{41}$ & 189 & - & - & - & - & KR653158 \\
\hline sh13 & $\begin{array}{l}\text { F: TGAAACAAGCACACTGTAATCA } \\
\text { R: GAGCAATAACTGTAAAGCGGTA }\end{array}$ & 40.8 & $(\mathrm{AC})_{51}$ & 363 & - & - & - & - & KR653159 \\
\hline
\end{tabular}

Locus name, primer sequences ( $F$ : forward, $R$ : reverse), annealing temperature $(\mathrm{Ta})$, repeat motif, allele size, number of polymorphic alleles per locus $\left(N_{\mathrm{A}}\right)$, polymorphic information content $(\mathrm{PIC})$, observed heterozygosity $\left(H_{\mathrm{O}}\right)$, expected heterozygosity $\left(H_{\mathrm{E}}\right)$, and GenBank accession Nos. are shown. *Significant deviations of locus from Hardy-Weinberg equilibrium after Bonferroni correction $(P<0.004545)$.

\section{RESULTS AND DISCUSSION}

From the microsatellite enrichment library of $S$. horrens, 110 positive clones were randomly selected for sequencing, and 80 microsatellite sequences were obtained; the positive rate of cloning was $72.72 \%$. As described by Zane et al. (2002), wide differences exist in the efficiency of microsatellite enrichment, ranging from 50\% (Passera lagia) to 95\% (Sparus aurata) based on the fast isolation method with amplified fragment length polymorphism of sequences containing repeats method. Most frequently encountered repeat motifs were di-nucleotides $(77 \%)$, followed by mononucleotides $(23 \%)$ and tetra-nucleotides (2\%). Interestingly, mononucleotide contigs were frequently observed, and the core base was repeated more than 10 times, such as for loci sh5, sh7, and sh10. These results may be related to the gene structure of different species, the type of probe, and the restriction enzyme. Thirteen microsatellite loci, including 11 polymorphic loci and 2 monomorphic loci, were isolated from the synthetic 43 pairs of specific primers after polymorphism testing.

All genetic data from the 11 polymorphic loci were analyzed and evaluated. The results showed that the number of polymorphic alleles per locus was 3-8 (total 40 alleles, mean 3.6). Observed heterozygosity $(0.1364-0.8966)$ was significantly lower than expected heterozygosity (0.1653-0.7551), which may be related to the Wahlund effect (Li et al., 2004), natural selection, and null alleles, particularly inbreeding. In addition, of the 11 polymorphicloci, 6 loci were in high polymorphism with polymorphic information content $>0.5$ according to the judgment standard (Botstein et al., 1980). Finally, 9 polymorphic loci were in Hardy-Weinberg equilibrium after 
application of Bonferroni correction (adjusted $\mathrm{P}=0.004545)$, except for 2 loci (sh1, sh3); no genotypiclinkage disequilibrium was observed. No genotyping error among the loci was detected.

In this study, we present a set of novel microsatellite markers in the sea cucumber $S$. horrens. This basic information will be used in our further studies of population and conservation genetic studies of $S$. horrens. Furthermore, the results will be useful for preserving the aquaculture of $S$. horrens and for enriching the phylogenetic analyses of the holothurians, which can also be applied to echinoderms.

\section{Conflicts of interest}

The authors declare no conflict of interest.

\section{ACKNOWLEDGMENTS}

Research supported by the National Natural Science Foundation of China (\#31272668), Natural Science Foundation of Fujian Province (\#2014J01133), and the Program for New Century Excellent Talents in Fujian Province University and the Foundation for Innovative Research Team of Jimei University, China (\#2010A004). The authors are also thankful for the team members of outreach activity on Trepang genetic stocks for providing wild samples of $S$. horrens.

\section{REFERENCES}

Baine M and Choo PS (1999). Sea cucumber fisheries and trade in Malaysia. In The conservation of sea cucumbers in Malaysia-their taxonomy, ecology and trade: proceedings of an international conference. Department of Agriculture, Kuala Lumpur, Malaysia, 49-63.

Beckmann JS and Weber JL (1992). Survey of human and rat microsatellites. Genomics 12: 627-631.

Botstein D, White RL, Skolnick M and Davis RW (1980). Construction of a genetic linkage map in man using restriction fragment length polymorphisms. Am. J. Hum. Genet. 32: 314-331.

Chen J (2003). Overview of sea cucumber farming and sea ranching practices in China. SPC Beche-de-mer Inf. Bull. 18: 18-23.

Chistiakov DA, Hellemans B and Volckaert FA (2006). Microsatellites and their genomic distribution, evolution, function and applications: a review with special reference to fish genetics. Aquaculture 255: 1-29.

Hearn A and Pinillos F (2006). Baseline information on the warty sea cucumber Stichopus horrens in Santa Cruz, Galápagos, prior to the commencement of an illegal fishery. SPC Beche-de-mer Inf. Bull. 24: 3-10.

Hu C, Li H, Xia J, Zhang L, et al. (2013). Spawning, larval development and juvenile growth of the sea cucumber Stichopus horrens. Aquaculture 404: 47-54.

Li Q and Wan JM (2005). SSRHunter: development of a local searching software for SSR sites. Hereditas 27: 808-810.

Li ZB, Li SJ and Wang GZ (2004). Heterozygosity in six populations of crab Scylla serrata. Oceanol. Limnol. Sin. 35: 363-369.

Massin C, Zulfigar Y, Tan Shau Hwai A and Rizal Boss SZ (2002). The genus Stichopus (Echinodermata: Holothuroidea) from the Johore Marine Park (Malaysia) with the description of two new species. Bull. L'Institut Royal Sci. Naturelles Belgique, Biol. 72: 73-99.

Rasolofonirina R, Mara E and Jangoux M (2005). Sea cucumber fishery and mariculture in Madagascar, a case study of Toliara, southwest Madagascar. FAO Fisheries Technical Paper, 133-150.

Rice WR (1989). Analyzing tables of statistical tests. Evolution 4: 223-225.

Schoppe S (2000). Echinoderms of the Philippines: A guide to common shallow water sea stars, brittle stars, sea urchins, sea cucumbers and feather stars. VISCA-GTZ Program on Applied Tropical Ecology, Visayas State College of Agriculture, Iloilo City.

Van Oosterhout C, Hutchinson WF, Wills DPM and Shipley P (2004). MICRO-CHECKER: software for identifying and correcting genotyping errors in microsatellite data. Mol. Ecol. Notes 4: 535-538.

Yeh FC, Yang R, Boyle TJ, Ye Z, et al. (2000). PopGene32, Microsoft Windows-Based freeware for Population Genetic analysis. Version 1.32. Molecular Biology and Biotechnology Centre. University of Alberta, Alberta. 
Yuan L, Xia J, Zhang L and Hu C (2012). Development of 16 microsatellite loci of the tropical sea cucumber Stichopus horrens with cross-amplification in the congeneric species Stichopus monotuberculatus. Conserv. Genet. Resour. 4: 303-305.

Zane L, Bargelloni L and Patarnello T (2002). Strategies for microsatellite isolation: a review. Mol. Ecol. 11: 1-16. 